\title{
EFFICACY OF CONCURRENT COGNITIVE-MOTOR TRAINING ON GAIT IN HEMIPARETIC CEREBRAL PALSY: A RANDOMIZED CONTROLLED TRIAL
}

\author{
Nevein Mohammed Gharib *1, Gehan Mosaad Abd-El Maksoud 2, Salah Eldin \\ Bassit Elsayed ${ }^{3}$.
}

${ }^{* 1}$ Assistant Professor, Physical Therapy Department for Neuromuscular Disorders and its Surgery, Faculty of Physical Therapy, Cairo University, Egypt.

${ }^{2}$ Assistant Professor, Physical Therapy Department for Growth and Development Disorders for Children and its Surgery, Faculty of Physical Therapy, Cairo University, Egypt.

${ }^{3}$ Lecturer, Department of Basic Science for Physical Therapy, Faculty of Physical Therapy, Cairo University, Egypt.

\section{ABSTRACT}

Background: Interference between cognitive tasks and motor control activities such as walking is crucial for functional enhancement in patients with neurological disorders. Therefore, both cognitive and motor training should be addressed in planning physical therapy programs.

Objective: To assess the efficacy of concurrent cognitive-motor training on gait in children with hemiparetic cerebral palsy.

Materials and Methods: Thirty children with hemiparetic cerebral palsy of both sexes (10-14 years) shared in this study. They were randomly assigned into two equal groups; experimental and control groups. Children in the experimental group received a traditional physical therapy exercise program in addition to a gait training program given concurrently with cognitive tasks. Those in the control group received the same traditional physical therapy and gait training programs without any concurrent cognitive tasks. Treatment was provided three times per week for three successive months. The participants received baseline and post-treatment assessments for dimension E of Gross M otor Function Measure (GM FM) and some gait parameters including: step length, walking speed, ambulation index and time of support on the affected side (\% of gait cycle).

Results: Children in both groups showed significant improvement post treatment in GM FM scores and all measured gait parameters $(p \varangle 0.05)$ with a higher improvement in the experimental group. After the intervention, between-group comparison revealed significant differences for ambulation index $(t=3.16, p=0.004)$ and time of support on the affected side $(t=3.61, p=0.001$ ) in favour of the experimental group. No significant between-group differences were found in GM FS scores, step length and walking speed ( $p>0.05)$.

Conclusion: Concurrent cognitive-motor training increased the chance of improving walking ability in children with hemiparetic cerebral palsy as compared to the motor training alone.

KEY WORDS: Cognitive-M otor Intervention, Cerebral Palsy, Hemiparesis, Gait, Concurrent Tasks.

Address for correspondence: Dr. Nevein M ohammed Gharib, PhD., Assistant Professor, Physical Therapy Department for Neuromuscular Disorders and its Surgery, Faculty of Physical Therapy, Cairo University, Egypt E-Mail: neveinmohammed@yahoo.com

\section{Access this Article online}

Quick Response code

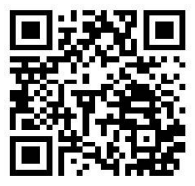

DOI: $10.16965 /$ ijpr.2016.206
International Journal of Physiotherapy and Research

ISSN 2321- 1822

www.ijmhr.org/ ijpr.html

Received: 17-12-2016 Accepted: 04-01-2017

Peer Review: 18-12-2016 Published (0): 11-02-2017

Revised: None
Published (P): 11-02-2017 


\section{INTRODUCTION}

Cerebral palsy (CP) is a non-progressive motor disorder with functional disability that occurs in about 2 per 1000 live births [1]. It results from a static injury to the developing brain [2]. Hemiplegia accounts for $35 \%$ of these children and results in abnormal motor control with associated delay in the onset of walking and an abnormal gait pattern [3].

Gait among children with hemiparetic $C P$ is often characterized by longer gait cycle and support phase, slower walking speed and reduced stride length and endurance during gait as compared to healthy children [4]. Hence, this may produce a less efficient automatic control during walking and subsequently increases the need to pay more attention while walking and might be more vulnerable to the effect of an imposed concurrent task than their normal peers [5].

The control of human walking has traditionally been considered an automatic process that only requires minimal cognitive effort. However, recent research showed evidence that the control of locomotion requires cognitive resources [6]. A child with CP may walk successfully in the clinical setting, but have difficulty walking at school or on the playground. Differences in the cognitive and perceptual demands of different settings may contribute to the lack of carryover as most environments are characterized by obstacles and various distracting auditory and visual stimuli [7].

Children often encounter situations involving the concurrent performance of a cognitive task while walking. For example, they may need to identify signs and signals on their way to school or talk to a friend and carry a book while walking. Research concerning people's ability to perform two tasks concurrently has referred to these types of situations as dual-task or multi-task situations. During these situations, the attention needs to be divided [8].

Cognitive-motor interference refers to the decrement in performance that occurs when cognitive and motor tasks are performed simultaneously [9] and it has been well established in children with CP [5]. Studies have proved that children with $\mathrm{CP}$, besides their motor impairments, have some executive and attention problems [10] in the form of having limitations in their attentional processing abilities as indicated by a reduced ability to inhibit responses to irrelevant stimuli when performing a task [11]. Additionally, they may also have a smaller working memory capacity than their normal peers [12].

M otor performance is the result of an interaction among cognitive, perceptual, mechanical and neurologic mechanisms [13]. Subsequently, interference between cognitive tasks and motor control activities (such as walking) is important for functional improvement in patients with neurological deficits such as CP. Therefore, the physical therapist must address both cognitive and motor training in planning rehabilitation therapy [14].

According to the task integration hypothesis, single-task training (such as motor training alone) has lower demands than simultaneous cognitive-motor training. Single task training does not permit the concurrent performance of two or three tasks, whereas concurrent cognitive-motor training allows the coordination of various tasks via the simultaneous performance of two or more tasks [15].

However, the majority of gait training for children with CP focuses on functional recovery via motor training alone (single-task), rather than simultaneous cognitive-motor training. To the best of our knowledge, no research has yet been conducted on the effects of concurrent cognitive-motor training on gait in children with hemiparetic CP. Therefore, the therapeutic approaches available currently fall short of addressing cognitive impairment. Thus, the present study aimed to investigate the efficacy of concurrent cognitive-motor training on gait in children with hemiparetic CP.

\section{MATERIALS AND METHODS}

Subjects: Thirty children with hemiparetic CP were recruited from the paediatric physical therapy outpatient clinic of the Faculty of Physical Therapy, Cairo University, Egypt after parental agreement to the participation in this study. Their ages ranged from 10 to 14 years old and they had a mild degree of spasticity in the affected lower limbs (M odified Ashw orth Scale 
score $<$ ) [16]. The children were categorized as level II of the Gross M otor Function Classification System (GM FCS) scale [17]. Children classified as level II of this scale climb stairs hold onto a railing and encounter constraints in walking on uneven surfaces, inclines and walking in crowds or confined spaces. The categorization of GM FCS was initially determined by parental report and then affirmed by a qualified physical therapist after observation of walking for each child.

All children were assessed for intelligence and general cognitive functioning by the use of Wechsler Intelligence Scale for Children (WISC), 4th edition [18]. They all had Intelligence Quotient (IQ) ranged from 85 to 110 according to WISC. Additionally, all children had normal vision and hearing and attended primary school in Egypt.

Children were excluded if they received botulinum toxin injection within the last six months or had deformities in the spine or the extremities. Also, they were excluded if they had previous neurological or orthopedic problems or surgeries of the spine or the lower extremities within one year, auditory or visual agnosia or marked language deficits.

Children were randomly assigned to one of two groups; experimental or control group using a computer-generated random number list. Children in the experimental group received a traditional physical therapy exercise program in addition to a gait training program given concurrently with cognitive tasks. Children assigned to the control group received the same traditional physical therapy and gait training programs without any concurrent cognitive tasks. Ethical approval was obtained from the ethics committee of the Faculty of Physical Therapy, Cairo University and each parent signed an informed consent form authorizing the child's participation. Prior to the start of the study, all study personnel were trained on administration of all test measures by the use of standardized protocols.

\section{INSTRUMENTATION}

a) Gross M otor Function M easure (GM FM) is a valuable observational standard for providing an estimate of gross motor function in children with
CP [19]. It was proved to have high levels of validity, reliability, and responsiveness in assessment of motor functions and effects of intervention in children with CP [20]. It consists of 88 items (GM FM -88) grouped into five dimensions. Each item of the test is scored on a 4-point scale and a percentage score is calculated for each dimension [21]. In the present study, dimension E (24 items) which evaluates the motor function during walking, running and jumping was selected as an outcome measure.

b) The Biodex Gait Trainer $2^{\mathrm{TM}}$ is a device used to evaluate and train walking ability in patients with gait impairments. It consists of a treadmill with an instrumented deck that evaluates some kinematic gait parameters. A high resolution colour touch screen is connected to the device to control the device settings. Furthermore, the device is supported by a serial interface which permits download of patient's data to the computer.

\section{Procedure}

a) For evaluation: The children in both groups were assessed before the start of training and at its end (after three months). This was done by the same evaluator who was blinded to which group each participant was allocated.

For evaluation of the gross motor function, GMFM-88 test was administered bare feet without assistive aids. In the present study, dimension E (24 items) was used to evaluate the motor function during walking, running and jumping for all children participated in the study. The test was applied according to its user's manual [22].

The Biodex Gait Trainer $2^{\mathrm{TM}}$ was used to assess gait parameters before and after intervention including: speed of walking $(\mathrm{m} / \mathrm{sec})$, step length (m), time of support on the affected side (recorded as \% of gait cycle) and ambulation index. Ambulation index is a compound score relative to 100 which depends on average step cycle and foot-to-foot time distribution [23].

Initially, each child was permitted to be acquainted with the gait trainer set up. The children's recognition with the device was guaranteed to stay away from any misinterpretation of any difference of the outcomes between the 
two groups which might be clarified by unfamiliarity of the children with the device. This was accomplished through asking each child to practice walking over the gait trainer and follow the movement of the tread belt for 3-5 minutes. This was repeated 2-3 times until the child became familiar with the device.

To begin the assessment procedure by the gait trainer, the tread belt of the device was permitted to increase gradually to 0.3 meter/hour. The speed was then increased slowly to a comfortable pace for each child. Once a comfortable pace was reached, data recording process was begun. The assessment session lasted for continuous 3 minutes where each child was instructed to walk continuously over the tread belt. At the end of the evaluation, the tread belt was allowed to slow gradually till it stopped. The results then can be shown on the display. This process was repeated 3 times, with a rest period in between. For each child, gait parameters were averaged over the trials for further data analyses.

b) For treatment: All children in both groups underwent a designed physical therapy exercise program (two hours, three sessions / week) over a period of three months. Each physiotherapy session was divided into two parts; conventional exercises and gait training exercises, each part lasted for one hour with a 15-minutes rest in between. The first part of the session included inhibition of abnormal movement pattern and facilitation of normal movement pattern based on neuro-developmental technique (NDT). Specific strengthening exercises were also given for weak muscles in the affected side. Exercises for improving postural reactions from standing position were also applied as a part of training. Stretching exercises to restore flexibility of tight muscles in the affected side were also part of the routine rehabilitation. These exercises were based on passive range of motion therapeutic exercises described by Kisner and Colby [24]. As regarding to the second part of the session, gait training exercise program was applied for all children in both groups for 60 minutes. Children in the experimental group received gait training program concurrently applied with selected cognitive tasks (dual \& triple-task conditioning), while those in the control group received the same gait training program but as a single task (without dual or triple-task conditioning). The gait training exercise program was as follows:

- Training to stand alone with one limb support to shift the weight onto the affected side

- Training to walk overcoming obstacles of different sizes (forward, backward and sideward).

- Training to walk between steppers.

- Training to walk on rollators.

- Training to walk on balance beam.

- Training to walk over ground with narrow base of support, with tandem and semi tandem walking (forward, backward and sideways).

- Training to walk over foam ground (forward, backward and sideways).

- Training to walk on wooden and soft ramps.

- Training to ascend and descend stairs, without holding, on alternate feet.

- Training to go down stairs with two feet per stair without holding on, if possible.

For the experimental group, cognitive tasks were given concurrently while performing the previous gait training exercises. They were selected according to related dual and triple-task research [25-31] and they were given as follows:

1 . For the $1^{\text {st }}$ two weeks: the children were instructed to do the following tasks:

a. Naming things such as animals, governorates, and men's names (e.g., mention name of men starts with letter " $A$ ", so the answers are: Ahmed, Ashraf, Ayman,......etc) (naming things $\&$ words task). This task was given concurrently with the gait training exercises for the first two weeks of the treatment period.

b. Imagining and telling the road direction (e.g., the road direction from home to the supermarket, stationary, mosque,....etc) (imagining task ) 2. For the 3rd and 4th weeks: the children were instructed to do the following tasks:

a. Listening to a list of five different digits (comprising two numbers each) from a lab top with a loud speaker followed by listening to a word list composed of five different words (comprising five letters each). Then, the child was asked to recall the digits (digits task).

b. Identifying voices or sounds heard from a lab top with a loud speaker such as identifying voices 
(child, woman, man) and identifying sounds (door close, hand clap, cat meow,....etc) (auditory discrimination task).

3. For the 5th and 6th weeks: the children were instructed to do the following tasks:

a. Reciting numbers, days, or months backward (e.g., from Friday to Saturday,.....etc) (N-Back task).

b. Randomly mentioning the numbers between 100 and 200 (random digit generation task)

4. For the 7th and 8th weeks: the children were instructed to do the following tasks:

a. Counting backward from specific start number (e.g., from 40) and subtracting two or three each time (counting backward by twos and threes task).

b. Naming the opposite direction of his action (e.g., to name "right" when he/she steps by the left foot) (opposite direction task).

For the next four weeks, the children were instructed to perform triple-task walking where they were instructed to walk and simultaneously do the following:

\section{For the 9th and 10th weeks:}

a. Naming things $\&$ words while carrying a tray $(40 \times 30 \mathrm{~cm})$ loaded with seven table tennis balls (naming/tray) followed by naming things \& words while unfastening and fastening a button having a diameter of $1 \mathrm{~cm}$ (naming/button).

b. Performing visual imaginary spatial task while carrying a tray (imaginary/tray) followed by performing the same task while unfastening and fastening a button (imaginary/button).

c. Instructing the child to perform the N-Back task while carrying a tray (N-Back / tray).

6. For the 11th and 12th weeks:

a. The child was instructed to perform the digits task while carrying a tray (digits/tray) followed by performing the same task while unfastening and fastening a button (digits/button).

b. Instructing each child to do the auditory discrimination task while carrying a tray (auditory/ tray) followed by performing the same task while unfastening and fastening a button (auditory/button).

c. Each child was asked to perform the counting backward task (by twos and threes) while

\section{carrying a tray (counting/tray)}

To familiarize the children with the gait training tools, exercises and concurrent cognitive tasks, each child was given one demonstration before starting the treatment sessions. Afterwards, each child was instructed to perform the gait training exercises concurrently with a) one cognitive task (dual-task conditions, for the first eight weeks of the treatment period) and b) two cognitive tasks (triple-task conditions, for the 9th till 12th weeks of the treatment period). To perform dual-task walking, the children were asked to walk and simultaneously perform one cognitive task such as naming animals. While triple-task walking, each child was instructed to walk and simultaneously do the following 1 ) name animals and carry a tray with balls (animals/tray), 2) listen to and memorize digits and carry a tray with balls (digits/tray) and 3 ) listen to and memorize digits and unfasten and fasten a button (digits/button). During performing the dual- and triple-task conditions, the children were not asked to prioritize any of the tasks.

Statistical analysis: Statistical analysis was conducted using SPSS for windows, version 23. Normal distribution of the data was confirmed using the Kolmogorov-Smirnov normality test. M ann-Whitney signed-rank test was utilized to compare the baseline evaluation of the degree of spasticity between the two groups. To accommodate the $\left(1^{+}\right)$modification for numeric analysis, grade $\left(1^{+}\right)$of spasticity according to Modified Ashworth Scale was recorded as 1.5 [32]. Paired student t-test was used to compare between the mean values of GM FM scores, gait parameters pre and post treatment within the same group. Comparison between the mean values of these variables as regarding to pre and post treatment in the two groups was performed using unpaired student t-test. A p-value $<0.05$ was considered as statistically significant.

\section{RESULT}

Fifty children were evaluated for potential enrolment. Of these, 15 were excluded as they did not meet the inclusion criteria and five children's parents declined to share in the study. Thus, of the original pool, thirty children with hemiparetic CP were included in the study ( 13 males and 17 females). Analysis of baseline values between 
the two groups revealed non-significant differences as regarding to age $(p=0.85)$, weight $(p=0.45)$, height $(p=0.66)$ and the degree of spasticity $(p=0.72)$. The demographic and clinical characteristics of children in the two groups are listed in Table 1.

There were statistically non-significant differences in the mean values of pre- treatment data of all variables being tested (dimension $E$ of GM FM scale and gait parameters) between the two groups ( $p>0.05)$. As regarding to dimension $E$ of GM FM scale, it was assessed in this study to evaluate the motor function during walking, running and jumping. Comparison of the pre and post-treatment values of GM FM scores revealed a significant improvement of dimension $\mathrm{E}$ in both groups $(p \varangle 0.05)$ (Table 2$)$. On the other hand, there was a statistically non-significant difference in dimension $\mathrm{E}$ scores between both groups post treatment $(p=0.06)$ (Table 3).

When comparing the baseline and post-treatment values of gait parameters (measured by the gait trainer) within each group, the results revealed a significant improvement of all parameters in both groups including: step length for both the affected and non-affected sides, walking speed, time of support on the affected side (recorded as a percent of gait cycle) and ambulation index ( $p \varangle 0.05$ ) (Table 2).

The analysis of gait parameters post treatment between both groups revealed significant differences in ambulation index $(p=0.004)$ and time of support on the affected side $(p=0.001)$. On the contrary, there were non-significant differences in walking speed $(p=0.32)$ and step length of both the affected $(p=0.33)$ and non-affected $(p=0.18)$ sides (Table 3$)$.

Table 1: Demographic and clinical data of participants in both groups.

\begin{tabular}{|c|c|c|c|c|}
\hline & $\begin{array}{l}\text { Experimental } \\
\text { group }(n=15)\end{array}$ & $\begin{array}{c}\text { Control group } \\
(n=15)\end{array}$ & t- value ${ }^{c} / Z$-value ${ }^{d}$ & $p$-value \\
\hline Age (years) ${ }^{a}$ & $12.10 \pm 1.16$ & $11.09 \pm 0.85$ & $-0.18^{c}$ & 0.86 \\
\hline Height $(\mathrm{cm})^{\text {a }}$ & $122.67 \pm 3.74$ & $123.4 \pm 5.17$ & $-0.45^{c}$ & 0.66 \\
\hline Weight $(\mathrm{kg})^{\mathrm{a}}$ & $36.60 \pm 2.64$ & $35.27 \pm 2.05$ & $-0.77^{c}$ & 0.45 \\
\hline \multicolumn{5}{|l|}{ Gender $^{b}$} \\
\hline Male & $6(40 \%)$ & $7(46.66 \%)$ & & \\
\hline Female & $9(60 \%)$ & $8(53.33)$ & & \\
\hline $\begin{array}{c}\text { Modified } \\
\text { Ashowrth Scale }^{\text {a }}\end{array}$ & $1.25 \pm 0.25$ & $1.5 \pm 0.50$ & $-0.35^{d}$ & 0.72 \\
\hline \multicolumn{5}{|l|}{ Affected side $^{b}$} \\
\hline Right & $9(60 \%)$ & $7(46.66 \%)$ & & \\
\hline Left & $6(40 \%)$ & $8(53.33 \%)$ & & \\
\hline
\end{tabular}

Values are mean $\pm \mathrm{SD}^{\mathbf{a}}$ or frequency $(\%)^{\mathbf{b}}$. Method of statistical analysis is in the form of independent sample t-testc. Method of statistical analysis is in the form of $U$ M ann-Whitney signed-rankd.

Table 2: Descriptive statistics and within group comparison of GM FM scale and gait parameters in both groups.

\begin{tabular}{|c|c|c|c|c|c|c|}
\hline & \multicolumn{2}{|c|}{ Experimental group (n=15) } & \multicolumn{2}{c|}{ Control group (n=15) } & \multicolumn{2}{c|}{ Change score } \\
\hline & Pre & Post & Pre & Post & Experimental & Control \\
\hline GMFM (dimension E) & $67.22 \pm 3.59$ & $80.36 \pm 3.92^{*}$ & $67.49 \pm 2.56$ & $77.30 \pm 4.53^{*}$ & $13.14 \pm 1.15$ & $9.81 \pm 5.23$ \\
\hline Step length (m) & \multicolumn{3}{|c|}{} \\
\hline Affected side & $0.37 \pm 0.06$ & $0.43 \pm 0.07^{*}$ & $0.36 \pm 0.05$ & $0.41 \pm 0.05^{*}$ & $0.06 \pm 0.02$ & $0.05 \pm 0.02$ \\
\hline Non-affected side & $0.33 \pm 0.06$ & $0.41 \pm 0.07^{*}$ & $0.32 \pm 0.04$ & $0.38 \pm 0.05^{*}$ & $0.08 \pm 0.03$ & $0.05 \pm 0.02$ \\
\hline Speed of walking (m/ sec) & $0.55 \pm 0.10$ & $0.65 \pm 0.10^{*}$ & $0.54 \pm 0.09$ & $0.62 \pm 0.08^{*}$ & $0.10 \pm 0.03$ & $0.08 \pm 0.04$ \\
\hline Ambulation index & $61.46 \pm 7.03$ & $72.20 \pm 6.27^{*}$ & $61.8 \pm 7.15$ & $64.93 \pm 6.3^{*}$ & $10.73 \pm 3.19$ & $3.13 \pm 3.44$ \\
\hline $\begin{array}{c}\text { Time of support on the } \\
\text { affected side (\%) }\end{array}$ & $36.40 \pm 4.1$ & $44.2 \pm 3.36^{*}$ & $35.13 \pm 5.31$ & $38.13 \pm 5.56^{*}$ & $7.8 \pm 1.7$ & $3.0 \pm 2.4$ \\
\hline
\end{tabular}

Values are mean \pm SD.

GM FM : Gross M otor Function M easure scale.

Pre: Pre-treatment evaluation.

Post: Post-treatment evaluation.

* Significant at $p<0.05$. 
Table 3: Comparison between both groups pre and post treatment (between group comparisons).

\begin{tabular}{|c|c|c|c|c|}
\hline & \multicolumn{2}{|c|}{ Pre } & \multicolumn{2}{c|}{ Post } \\
\hline & $\mathrm{t}$-value & $\mathrm{p}$-value & $\mathrm{t}$-value & $\mathrm{p}$-value \\
\hline GM FM (dimension E) & -0.24 & 0.81 & 1.97 & 0.06 \\
\hline Step length (m) & \multicolumn{4}{|c|}{} \\
\hline Affected side & 0.61 & 0.54 & 0.98 & 0.33 \\
\hline Non-affected side & 0.33 & 0.74 & 1.35 & 0.18 \\
\hline Speed of walking (m/ sec) & 0.41 & 0.67 & 1.02 & 0.32 \\
\hline Ambulation index & -0.13 & 0.89 & 3.16 & $0.004^{*}$ \\
\hline $\begin{array}{c}\text { Time of support on the } \\
\text { affected side (\%) }\end{array}$ & 0.73 & 0.47 & 3.61 & $0.001^{*}$ \\
\hline
\end{tabular}

GM FM : Gross M otor Function M easure scale.

Pre: Pre-treatment evaluation.

Post: Post-treatment evaluation.

* Significant at $p<0.05$.

\section{DISCUSSION}

Exercise interventions that incorporate exercises to improve walking abilities have been often recommended for children with $\mathrm{CP}$ [33]. However, with physical exercise alone the additional cognitive requirements of safe walking cannot be addressed. Two recent reviews discussed the interplay between physical functions and cognition [34,35]. Both brought out the importance to combine physical and cognitive training into clinical practice to enable safer movement in physical environment. Thus, cognitive elements should be taken into account when designing an exercise regimen with the aim to preserve or improve walking performance in children with $\mathrm{CP}$.

This study was conducted to assess the efficacy of concurrent cognitive-motor training on walking ability in children with hemiparetic CP as compared to motor training alone. The children were randomly assigned into experimental and control groups. Children in the experimental group received a traditional physical therapy exercise program in addition to a gait training program given concurrently with cognitive tasks (cognitive-motor training). However, children assigned to the control group received the same traditional physical therapy and gait training programs but without any concurrent cognitive tasks (motor training alone). Pre-training and post-training were compared within and between the two groups.

The findings in this research revealed a significant improvement post-treatment in both groups as regards to gait in terms of GMFM scale (dimension E) and all measured gait parameters including step length of the affected and non-affected sides, walking speed, ambulation index and time of support on the affected side with greater improvement in the experimental group.

The significant improvement in GM FM scores and all measured gait parameters post treatment in both groups might be attributed to the effect of the designed physical therapy exercise program which was performed by the children in both groups. This exercise program included conventional exercises (based on NDT) followed by gait training program. The exercise program was directed to improve voluntary control on the muscles of the affected lower limb and trunk, control the unnecessary muscle activity, facilitate normal movement pattern, improve balance and maintain flexibility of the tight muscles in the affected side. This comes in agreement with the findings of a previous study which proved the efficacy of NDT on the walking abilities of children with $\mathrm{CP}$ who are ambulatory in terms of improving step length, stride length and velocity [36]. Also, Dodd et al [37] reported that proper training programs can lead to lasting changes in the strength of lower-limb muscles that may impact on the daily function for children with CP. M oreover, the program focused on improving weight bearing on the affected side and challenging balance while walking. This helped the child to achieve a better postural control during walking. Subsequently, this allowed further control over the muscles of the affected lower limb during both concentric and eccentric activity needed during gait. This facilitated the child to produce a longer step length, increase walking speed and time of support on the affected side and consequently improve ambulation index and GM FM scores. This explanation is in consistent with the findings of Cage and Novacheck [33]. Also, Kamm et al [38] reported that the development of postural control during locomotion, force the child to utilize the appropriate systems and sub-systems to promote the most efficient progress towards stability and control.

After the intervention, between-group comparison revealed non-significant differences for 
GMFM score, step length of the affected and non-affected sides and walking speed. However, there was a significant difference between both groups as regards to the ambulation index and time of support on the affected side in favour of the experimental group. This might be attributed to the effect of concurrent cognitive-motor training given to the participants in the experimental group. Thus, this substantiates the hypothesis that an additional cognitive challenge should be preferably part of a training program aiming to improve physical functioning in children with $\mathrm{CP}$.

Yet, to our knowledge, no other research has investigated training-specific effects on gait after concurrent cognitive-motor training in children with hemiparetic CP. Nonetheless, other studies have been conducted on adult patients with stroke to determine the efficacy of concurrent cognitive tasks on their walking abilities $[39,40]$ and similar findings had been achieved. It was reported that 4 weeks of a dual-task training program effectively improved balance, and walking abilities of patients with strokeinduced hemiplegia [39]. M oreover, Kim et al [40] conducted a study to determine the effects of dual-task training on cognitive and walking abilities of chronic stroke patients. They concluded that dual-task training subjects' performance was better than single-task training subjects' performance. Both training groups exhibited significant improvements in walking speed in the Timed Up and Go Test and 10-M eter Walk Test. However, dual-task group showed higher increases in dynamic gait index than the single-task group. On the other hand, Plummer et al [41] conducted a case series study to evaluate the efficacy of cognitive-motor dual-task gait training in patients with chronic stroke. They found that some of the participants did not demonstrate remarkable improvements in singletask walking speed after the intervention. This can't affect the results of our study because of the nature of the case series that limits the generalizability of the findings to other individuals.

The difference in the response pattern to concurrent tasks between children with $\mathrm{CP}$ and other patients with acquired brain damage (such as adult hemiplegia) can be explained by the suggested motor learning model which includes three phases; the cognitive, associative and automatic phase. Perfection in a motor skill is associated with a decline in the attention resources needed to perform the skill. In the third and final phase, the motor skill requires only a minimal amount of attention and the skill becomes automated [42]. For patients who have to (re)learn a lost motor skill such as walking, for example patients with stroke inducedhemiplegia, higher levels of attention are required to perform this skill [43]. On the contrary, children with CP aged $10-14$ years with level II on GM FCS, who experienced walking for years, the attention required for walking is rather low. Therefore, concurrent cognitive-motor training programs can be beneficial in generating attention at the start of the task which continues till its end. They are effective in triggering the conscious control mechanisms and attention strategies and reduce automatic control during activities [44].

Research has proved that attention is effective in generating cortical plasticity in the primary somatosensory and motor cortex and improvement in the motor memory. Consequently, these produce enhancement of the neural processing mechanisms required for proper task performance $[45,46]$. This comes in agreement with Wright and Shea [47] who concluded that attention is critical for the development of motor control. This is because both of attention and perception provide the stimulus for motor activity and vice versa. Additionally, it was reported that cognitive abilities together with physical practice has been appeared to have a beneficial effect in enhancing motor performance than physical practice alone. This implies that cognitive abilities cause priming of the motor cortex and appropriate activation of the neuromotor pathways [48]. This was affirmed by the conclusion that cognitive training may assist the child to enhance attention and concentration subsequently improves his motor performance. This type of training can be considered as a kind of feedback during motor performance till its end, which permits the child to pass to motor learning process and keep away from any errors during the motor planning process [49]. 
Reason and Mycielska [50] reported that dual task training let the threshold of attention to be low which mean that the central nervous system becomes ready enough for correction of motor errors. Therefore, practice of cognitive tasks concurrently during walking feed the central nervous system with enough flow of impulses help to correct the motor disturbance during walking and improve the walking performance.

Additionally, the concurrent cognitive-motor training given to the experimental group in this study was high intensity task specific training with much more difficulty than single-task motor training that was given to the participants in the control group. Therefore, the walking abilities of the participants in the experimental group were continually challenged, and this may have resulted in improved motivation, self-efficacy and confidence in performing the post-treatment GM FM and gait assessments at the end of the treatment period. This comes in accordance with the conclusion drawn by Silsupadol et al [51].

There are specific limitations of the study that should be considered in the interpretation of the results. First, the small size of the studied sample may limit the generalization of the study results. The age of the children who shared in this study was between 10-14 years. Future studies are recommended to target different age groups to help comparison of the results across different ages. The lack of follow-up for the participants in both groups might be considered another limitation. Therefore, similar studies are suggested to detect the long term effects of concurrent cognitive-motor training on gait. Also, during the application of this study, we did not include cognition as a variable to be assessed pre and post intervention. In future, it would be of interest to determine whether concurrent cognitive-motor training has any effect on cognitive domains in children with hemiparetic $C P$, such as executive function. Additionally, other studies are advocated to evaluate the effects of concurrent cognitive-motor training in children with CP from different viewpoints depending on activities of daily living.

\section{CONCLUSION}

In conclusion, the findings of this study revealed the potential benefits of concurrent cognitivemotor training in the rehabilitation of children with CP. The concurrent cognitive-motor training improved the walking ability of children with hemiparetic CP more than the motor training alone in terms of improving GM FM score and gait parameters. Therefore, concurrent cognitive-motor training should be included in the comprehensive management for children with CP.

\section{ACKNOWLEDGEM ENTS}

Sincere thanks to all children and their parents who shared in this study for their enthusiasm and patience during our extensive training and testing interventions. We would like also to thank our colleagues in paediatric physical therapy outpatient clinic of the Faculty of Physical Therapy, Cairo University for their generous help.

\section{Conflicts of interest: None}

\section{REFERENCES}

[1]. Odding E, Roebroeck M E, Stam HJ. The epidemiology of cerebral palsy: incidence, impairments and risk factors. Disabil Rehabil 2006;28(4):183-191.

[2]. Tosun A, Gökben S, Serdaroðlu G, Polat M, Tekgül H. Changing views of cerebral palsy over 35 years: the experience of a center. Turkish J Pediatr 2013; 55:815.

[3]. Wiklund LM , Uvebrant P: Hemiplegic cerebral palsy. Correlation between CT morphology and clinical findings. Dev Med Child Neurol 1991; 33(6): 512523.

[4]. Wang X, Wang Y. Gait analysis of children with spastic hemiplegic cerebral palsy. Neural Regen Res 2012;15(7):1578-1584.

[5]. Katz-Leurer M, Rotem H, M eyer S. Effect of concurrent cognitive tasks on temporo-spatial parameters of gait among children with cerebral palsy and typically developed controls. Dev Neurorehabil 2014;17(6):363-367.

[6]. BeurskensR, Bock O. The role of executive functions and memory in dual-task walking: a review. Neural Plasticity 2012;2012:1-9.

[7]. Mulder T, Pauwels J, Nienhuis B. Motor recovery following stroke: towards a disability-orientated assessment of motor dysfunctions. In: Harrison M, ed. Physiotherapy in Stroke M anagement. Edinburgh: Churchill Livingstone; 1995:275-282.

[8]. Schaefer S, Lövden M, Wieckhorst B, Lindenberger $U$. Cognitive performance is improved while walking: Differences in cognitive-sensorimotor couplings between children and young adults. Eur J Dev Psychol 2010;7(3):371-389. 
[9]. Woollacott M, Shumway-Cook A: Attention and the control of posture and gait: a review of an emerging area of research. Gait Posture 2002;16:1-14.

[10]. Bottcher L, Flachs EM, Uldall P. Attentional and executive impairments in children with spastic cerebral palsy. Dev M ed Child Neurol 2010;52:e42-e47.

[11]. Christ SE, White DA, Brunstrom JE, Abrams RA. Inhibitory control following perinatal brain injury. Neuropsychology 2003;77(1):171-178.

[12]. Reilly DS, Woollacott M H, van Donkelaar P, Saavedra $S$. The interaction between executive attention and postural control in dual-task conditions: children with cerebral palsy. Arch Phys Med Rehabil 2008;89(5):834-842.

[13]. Huang HJ, Mercer VS. Dual-task methodology: application in studies of cognitive and motor performance in adults and children. Pediatr Phys Ther 2001;13(3):133-140.

[14]. Haggard P, Cockburn J, CockJ, Fordham C, Wade D. Interference between gait and cognitive tasks in a rehabilitating neurological population. J Neurol Neurosurg Psychiatry 2000;69:479-486.

[15]. Silsupadol P, Siu KC, Shumway-Cook A, Woollacott $\mathrm{MH}$. Training of balance under single- and dualtask conditions in older adults with balance impairment. Phys Ther 2006;86:269-281.

[16]. Bohannon RW, Smith M B. Interrater reliability of a modified Ashworth scale of muscle spasticity. Phys Ther 1987;67(2):206-207.

[17]. Palisano R, Cameron D, Rosenbaum P, Walter SD, Russel D. Stability of the Gross M otor Function Classification System. Dev Med Child Neurol 2006;48:424-28.

[18]. Hagmann-von Arx P, Manicolo O, Perkinson-Gloor $N$, Weber P, Grob A, Lemola S. Gait in Very Preterm School-Aged Children in Dual-Task Paradigms. PLOS One 2015;10 (12): e0144363.

[19]. Russell DJ, Rosenbaum PL, Avery LM , Lane M. Gross M otor Function M easure (GM FM -66 and GM FM -88) User's M anual. London, United Kingdom: M ac Keith Press; 2002.

[20]. Bjornson KF, Graubert CS, Buford VL, M cLaughlin J. Validity of the gross motor function measure. Pediatr Phys Ther 1998;10:43-47.

[21]. Brunton LK, Bartlett DJ. Validity and Reliability of Two Abbreviated Versions of the Gross M otor Function M easure. Phys Ther 2011;91(4):577-588.

[22]. Russell DJ, Rosenbaum PL, Gowland C, Hardy S, Lane $M$, Plews N, et al. Gross M otor Function Measure manual, second edition. Hamilton, ON, Canada, M cMaster University: Can Child Centre for Childhood Disability Research; 1993.

[23]. Robinson BS, CookJL, Richburg CM and Price SE. Use of an electrotactile vestibular substitution system to facilitate balance and gait of an individual with gentamicin-induced bilateral vestibular hypofunction and bilateral transtibial amputation. J Neurol Phys Ther 2009;33:150-159.

[24]. Kisner C, Colby LA. Therapeutic exercise: Foundation and techniques, sixth edition. Philadelphia: F.A. Davis Company; 2012.

Int J Physiother Res 2017;5(1):1852-62. ISSN 2321-1822
[25]. Bloem BR, Valkenburg VV, Slabbekoorn M, van Dijk JG. The multiple tasks test. Strategies in Parkinson's disease. Exp Brain Res 2001;137:478-486.

[26]. Erikson C, Allert C, Carlberg EB, Katz-Salomon M. Stability of longitudinal motor development in very low birthweight infants from 5 months to 5.5 years. Acta Paediatr 2003;92:197-203.

[27]. Dubost V, Kressig RW, Gonthier R, Herrmann FR, Aminian K, Najafi B, Beauchet O. Relationships between dual-task related changes in stride velocity and stride time variability in healthy older adults. Hum Mov Sci 2006;25:372-382.

[28]. Leitner Y, Barak R, Giladi N, Peretz C, Eshel R, Gruendlinger L, HausdorffJM. Gait in attention deficit hyperactivity disorder: effects of methylphenidate and dual tasking. J Neurol 2007;254:1330-1138.

[29]. Yang YR, Chen YC, Lee CS, Cheng SJ, Wang RY. Dualtask-related gait changes in individuals with stroke. Gait Posture 2007;25:185-190.

[30]. Cherng RJ, Liang LY, Chen Y], Chen Y]. The effects of a motor and a cognitive concurrent task on walking in children with developmental coordination disorder. Gait Posture 2009;29:204-207.

[31]. Muhaidat J, Kerr A, Evans JJ, Skelton DA. Exploring gait-related dual-task tests in community-dwelling fallers and non-faller: a pilot study. Physiother Theory Pract 2013;29:351-370.

[32]. Friedman A, Diamond M, Johnston MV, Daffner C. Effects of botulinum toxin $A$ on upper limb spasticity in children with cerebral palsy. Am J Phys Med Rehabil 2000;79(1):53-59.

[33]. Cage JR, Novacheck TF. An update on the treatment of gait problems in cerebral palsy. J Pediatr Orthop Part B 2001;10:265-274.

[34]. Pichierri G, Wolf P, M urer K, de Bruin ED: Cognitive and cognitive-motor interventions affecting physical functioning: a systematic review. BM C Geriatr 2011;11:29-48.

[35]. Segev-Jacubovski O, Herman T, Yogev-Seligmann G, M irelman A, Giladi N, Hausdorff JM: The interplay between gait, falls and cognition: can cognitive therapy reduce fall risk? Expert Rev Neurother 2011;11(7):1057-1075.

[36]. Adams MA, Chandler LS and Schuhmann K. Gait changes in children with cerebral palsy following a neurodevelopmental treatment course. Pediatr Phys Ther 2000;12:114-120.

[37]. Dodd K, Taylor N and Graham H. A randomized clinical trial of strength training in young people with cerebral palsy. Dev Med Child Neurol 2003;45:652-657.

[38]. Kamm K, Thelen E, Jensen J. A dynamical system approach to motor development. Phys Ther 2005;70(12):17-29.

[39]. Seo TH, Lee BH, BaekJY: The effect of dual task training on the balance and gait of stroke patients. J Coaching Dev 2010;12:139-49.

[40]. Kim GY, Han M R, Lee HG. Effect of dual-task rehabilitative training on cognitive and motor function of stroke patients. J Phys Ther Sci 2014;26(1):1-6. 
[41].Plummer P, Villalobos RM, Vayda MS, Moser $M$, Johnson E. Feasibility of dual-task gait training for community-dwelling adults after stroke: a case series. Stroke Res Treat 2014;2014:1-12.

[42]. Fitts PM, Posner MI. Human performance, 1st ed. Belmont: Brooks/Cole; 1967.

[43]. Cockburn J, Haggard P, Cock J, Fordham C. Changing patterns of cognitive-motor interference (CMI) over time during recovery from stroke. Clinic Rehab 2003;17:167-173.

[44]. Wulf G, Landers M , Lewthwaite R, Töllner T. External focus instructions reduce postural instability in individuals with Parkinson disease. Phys Ther 2009;89(2):162-168.

[45]. Lewis M M, Slagle CG, Smith AB, Truong Y, Bai $P$, McKeown MJ, et al. Task specific influences of Parkinson's disease on the striato-thalamo-cortical and cerebello-thalamo-cortical motor circuitries. Neuroscience 2007; 147 (1): 224-235.

[46]. Holschneider DP, Yang J, Guo Y, M aarek JM . Reorganization of functional brain maps after exercise training: importance of cerebellar-thalamic-cortical pathway. Brain Res 2007;1184:96-107.
[47]. Wright DL, Shea $\mathrm{CH}$. Cognition and motor skill acqusition: Contextual dependencies. In Cognitive assessment: a multidisciplinary perspective. Edited by Reynolds CR. New York: Plenum; 1994:89-106.

[48]. Anderson JR. Acqusition of cognitive skill. Psychol Review 1982;89(4):369-406.

[49]. Wickens CD, Hollands JG, Banbury S, Parasuraman R. Engineering Psychology and Human Performance, 4th ed. New York: Pearson; 2012.

[50]. Reason J, M ycielska K. Absent minded?: Psychology of mental lapses and everyday errors. Engle Wood Cliffs NJ: Prentice-Hall; 1982.

[51]. Silsupadol P, Shumway-Cook A, Lugade V, van Donkelaar P, Chou LS, Mayr U, Woollacott MH. Effects of single-task versus dual-task training on balance performance in older adults: a doubleblind, randomized controlled trial. Arch Phys Med Rehabil 2009;90:381-87.

How to cite this article:

Nevein Mohammed Gharib, Gehan M osaad Abd-El Maksoud, Salah Eldin Bassit Elsayed. EFFICACY OF CONCURRENT COGNITIVE-M OTOR TRAINING ON GAIT IN HEM IPARETIC CEREBRAL PALSY: A RANDOM IZED CONTROLLED TRIAL. Int J Physiother Res 2017;5(1):1852-1862. DOI: 10.16965/ ijpr.2016.206 